\title{
The Faith-Based Advantage: A Case Study on the Adventist Development \& Relief Agency's Response to Humanitarian Impacts of COVID-19 as a Faith-Based Organization
}

\author{
Emily Hirata ${ }^{a}$, Michael Peach ${ }^{b}$, Sharon Tobing ${ }^{c}$ \\ ${ }^{a}$ MPH, Technical Advisor for Health \& Nutrition, ADRA International \\ ${ }^{b}$ MPA, Global Emergency Coordinator, ADRA International \\ ${ }^{\mathrm{C}} \mathrm{MPH}$, Senior Technical Advisor for Health, ADRA International
}

\begin{abstract}
Large-scale health emergencies like COVID-19 oftentimes result in widespread humanitarian impacts. Due to their long-standing relationships and involvement within local communities, along with extensive networks and support from faithaffiliated institutions, faith-based NGOs carry a unique advantage in reaching the most vulnerable during such crises. The Adventist Development \& Relief Agency's (ADRA) experience during its global COVID-19 response showcases how keeping a local presence in-country and fostering partnerships with affiliated faith institutions and constituents can result in a wide reach of programming. By providing dedicated personnel and small seed-funding, developing a flexible global strategy involving strong business continuity plans and emphasis on its faith base, and supporting the sharing of information and lessons learned among local offices, faith-based NGOs are capable of quickly delivering life-saving interventions to vulnerable communities. ADRA and the affiliated Seventh-day Adventist Church have proved during the first year of COVID-19 that they are stronger together, highlighting the importance of utilizing a faith base when implementing humanitarian interventions.
\end{abstract}

Key Words: faith-based organizations, global health, humanitarian response, COVID-19, Seventh-day Adventist

\section{Introduction}

Large-scale health emergencies such as epidemics and pandemics can result in widespread humanitarian need for vulnerable populations. While already at heightened risk of poorer health outcomes directly related to the health emergency at hand, vulnerable populations are also disproportionately at risk of suffering secondary humanitarian impacts as well. ${ }^{1-3}$ Secondary impacts seen during COVID-19 and other major outbreaks include economic instability and livelihood disruptions, food insecurity and malnutrition, health system stress/collapse, expanded need for psychosocial support, educational delays, increased child labor, hindered access to basic services, and the rise of violence and abuse. ${ }^{2-14}$ 
Faith-based non-governmental organizations (NGOs) have the potential to leverage mobilization for humanitarian response to reach the needs of vulnerable communities that may otherwise be overlooked during large-scale health emergencies. Oftentimes, faith-based NGOs have long-standing relationships and involvement within local communities, are trusted more than local secular institutions, and frequently have the ability to provide services of better quality than counterpart government and non-government organizations. ${ }^{15-18}$ Moreover, faith-based NGOs often have extensive networks with other faith and development institutions, creating a unique position from which to form collaborations and deliver support in times of humanitarian crisis. ${ }^{18}$ The Charter for Faith-based Humanitarian Action, endorsed in Istanbul during the World Humanitarian Summit, has recognized this 'unique position and comparative advantage' of local faith actors in humanitarian settings, particularly given they are embedded in society, before, during, and long after crises occur. ${ }^{19}$

The Adventist Development and Relief Agency (ADRA) is one such faith-based NGO that has been providing humanitarian support during the COVID-19 pandemic. ADRA is the official humanitarian branch of the global Seventh-day Adventist (SDA) Church and comprises a network of locally-registered offices in 118 countries, delivering assistance through localized on-the-ground approaches within the communities in which these offices are based. ${ }^{20}$ Seasoned in emergency response and capitalizing on its faith-based structure, the network of ADRA country offices banded together at the onset of the COVID-19 outbreak to develop and implement the "Stronger Together" global COVID-19 response, successfully supporting millions of pandemic-affected people across the globe.

\section{Methods}

Previous to the COVID-19 pandemic, ADRA interventions did not operate under one single overarching action plan to address humanitarian crises. Yet, with the scale and extent to which COVID-19 was impacting the globe, ADRA's network of local country offices joined together as one body to implement its "Stronger Together" global response. This joint global response consisted of four key elements: 1) creation of a global COVID19 Taskforce; 2) development of ADRA's "Stronger Together" COVID-19 Framework and Response Strategy; 3) provision of seed funding to kickstart projects under the response strategy; and 4) creation of the COVID-19 Technical Interest Group to provide supplementary technical knowledge and materials to country offices.

Data on each of the four key elements was collected through analyzing ADRA's global response reports and meeting minutes, studying existing strategic documents for the global response, and analyzing transcripts from an interview conducted with ADRA's Global Emergency Coordinator. Further information was collected to make comparisons to pre-pandemic performance, as well as to the general state of other organizations in the sector during the first year of pandemic, through review of annual reports and news articles.

\section{COVID-19 Taskforce}

During March 2020, ADRA established a COVID-19 Taskforce to organize and manage its global response. The Taskforce was comprised of key leadership within ADRA at the international Vice President level along with experienced program management professionals from across the global ADRA network of country offices. The Taskforce prioritized strengthening operational capacity, promoting staff wellbeing, adapting to new ways of working, supporting local SDA Churches, capturing lessons learned, and leveraging funds. For the first several weeks after its establishment, the COVID-19 Taskforce met daily over virtual online platforms to collaborate and develop ADRA's global response strategy. 
Figure 1: ADRA's "Stronger Together" Global COVID-19 Strategy

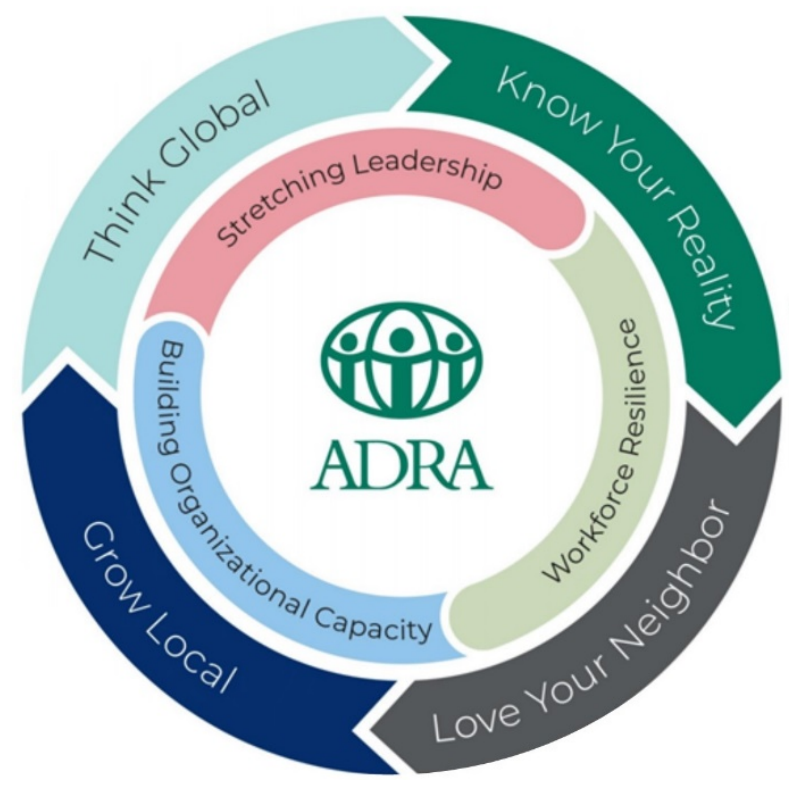

\section{"Stronger Together" COVID-19 Framework and Response Strategy}

Given ADRA's presence in a wide variety of contexts, rather than a one-size-fits-all approach, ADRA created a flexible strategy (Figure 1) based on a framework of four simple pillars (Table 1) developed specifically for the COVID-19 crisis, which could be applied in any local office:

1. Know Your Reality: ADRA realized the agency's impact could only be effective if its staff, volunteers, and partners understood their own risks and took the appropriate measures to mitigate and address them. At an

July 2021. Christian Journal for Global Health 8(1) organizational level, ADRA offices also needed to understand the disruptions the pandemic would bring to their current operations and pivot existing projects where necessary to address COVID-19.

2. Love Your Neighbor: While adhering to social responsibility, valuing and providing protection, and in consideration of pandemic restrictions, ADRA was intentional in strengthening connections with the SDA Church and other entities to further extend its reach to the most vulnerable.

3. Grow Local: ADRA enabled local networks and leadership, as well as fostered economic recovery and resilience. Offices were advised to "think outside the box" of external funding, highlighting the focus on providing local solutions to local problems. This meant being intentional about mapping assets and understanding how to leverage existing resources through local partnerships.

4. Think Global: Understanding that ADRA's global network of offices would be "stronger together," this fourth pillar built common purpose in ADRA's worldwide office network for a global COVID-19 response. The SDA Church and ADRA hold a presence in 118 countries, with a global church membership of 22 million people, and this advantage was to be explored to leverage greater impact and develop innovative solutions that could be shared and adapted based on local contexts. 
Table 1. ADRA “Stronger Together” COVID-19 Global Strategy Framework

\begin{tabular}{|c|c|}
\hline $\begin{array}{l}\text { Know Your Reality } \\
\text { Understand personal and professional risk } \\
\text { Pursue new business opportunities }\end{array}$ & $\begin{array}{l}\text { Love Your Neighbor } \\
\text { Build connections with the community } \\
\text { Support the most vulnerable }\end{array}$ \\
\hline $\begin{array}{l}\text { Activities to include: } \\
\text { - Undertaking risk assessments } \\
\text { - } \quad \text { Developing business continuity plans } \\
\text { - } \quad \text { Undertaking training needs analysis for staff } \\
\text { - } \quad \text { Participating in relevant COVID-19 online learning forums } \\
\text { - } \quad \text { Agreeing what successful response looks like with staff and } \\
\text { - } \quad \text { Under stakeholders } \\
\text { - } \quad \text { Engaging and sharing information with government and } \\
\text { - } \quad \text { Influencing donors and supporters with regular } \\
\text { communication }\end{array}$ & $\begin{array}{l}\text { Activities to include: } \\
\text { - } \quad \text { Developing implementation strategies aligned with ADRA's } \\
\text { priority sectors } \\
\text { Exploring technology and innovations to enhance program } \\
\text { delivery } \\
\text { Explore partnerships with the SDA Church and other faith } \\
\text { communities } \\
\text { Mainstream accountability and safeguarding in all project } \\
\text { - } \text { activities } \\
\text { - } \text { Adomoting the application of humanitarian standards } \\
\text { Partnering with church and commercial media channels to } \\
\text { disseminate information materials promoted by the World } \\
\text { Health Organization and other health authorities } \\
\text { Prioritizing the physical and mental wellbeing of staff and } \\
\text { volunteers }\end{array}$ \\
\hline $\begin{array}{l}\text { Grow Local } \\
\text { Enable local networks and leadership } \\
\text { Foster economic recovery and resilience }\end{array}$ & $\begin{array}{l}\text { Think Global } \\
\text { Build common purpose in the ADRA office network for a global } \\
\text { COVID-19 response } \\
\text { Advocate to think global, but act local }\end{array}$ \\
\hline $\begin{array}{l}\text { Activities to include: } \\
\text { - } \quad \text { Building and maintaining a volunteer capability } \\
\text { - } \quad \text { Developing early recovery plans for local offices and partner } \\
\text { - } \quad \text { Exploring local and sustainable fundraising opportunities } \\
\text { - } \quad \text { Developing a return-to-work strategy for staff and volunteers } \\
\text { - Partnering with local civil society organizations and the SDA } \\
\text { Church and other faith communities to coordinate planning } \\
\text { and implementation } \\
\text { Exploring opportunities to shift resources and decision- } \\
\text { making to indigenous local civil society organizations and } \\
\text { governments } \\
\text { Exploring technology to foster social enterprise and cash } \\
\text { transfers to support economic recovery } \\
\text { Encouraging effective performance through simple } \\
\text { monitoring, evaluation, accountability, and learning (MEAL) } \\
\text { frameworks }\end{array}$ & $\begin{array}{l}\text { Activities to include: } \\
\text { - Using the global footprint of ADRA and the SDA Church to } \\
\text { advocate for the most vulnerable } \\
\text { - Aligning with SDA Church strategies for community service } \\
\text { and outreach } \\
\text { - Contributing local data to ADRA headquarters to demonstrate } \\
\text { global impact } \\
\text { - Actively promoting ADRA's global marketing and } \\
\text { development campaigns to encourage efficient local fundraising } \\
\text { Utilizing the ADRA Technical Learning Labs for resources and } \\
\text { - } \quad \text { Repport } \\
\text { - } \\
\text { Regularly reviewing ADRA structures to ensure agile and } \\
\text { effective response } \\
\text { Leveraging coordination mechanisms available through UN } \\
\text { agencies to share information and seek funding opportunities. }\end{array}$ \\
\hline
\end{tabular}

Foundational to this framework were three precepts by which ADRA was to function within each pillar:

1. Workforce Resilience. ADRA recognized its own staff needed to be cared for so they could care for others. Using a multi-layered support structure, workforce resilience was promoted by compassionate leadership to provide for the basic safety, security, and wellbeing of ADRA's staff; deliver a safe, productive, and

flexible work environment; and build a stronger workplace culture that prioritizes psychological safety in light of COVID-19 stressors. Practical tools were also developed and disseminated to the ADRA country office network to facilitate business continuity planning and flexible workforce employment strategies.

2. Building Organizational Capacity. ADRA's management and leadership at the country, 
regional, and global levels were considered vital to navigating the numerous issues resulting from COVID-19. This provided the opportunity to confer with the broader ADRA workforce to ensure a team approach to meet the immediate and future needs of each office.

3. Stretching Leadership. ADRA believes that every leader in the agency has the opportunity to lead with courage during uncertain times. As the pandemic has changed the way humanitarian interventions can be implemented, leadership has also needed to evolve. The changing needs and expectations of leadership during the COVID-19 crisis necessitated clear and courageous plans for competency alignment and development.

As the length of how long the pandemic would last was unknown at the time of development, the strategy was set to expire in March 2021, with plans to develop a revised strategy if needs were to continue. Given the pandemic's ongoing impacts, a revised strategy has been established, building on the previous pillars and precepts, while adding more intentional focus on health, education, and livelihoods sectors.

\section{Seed Funding}

To kickstart the global strategy developed by the COVID-19 Taskforce, ADRA's headquarters provided $\$ 2.5$ million to support the process and get projects running within one month of establishment - by April 2020. Country offices submitted proposals to the Taskforce for small funding. Proposals were vetted to ensure quality design and capacity before receiving approval for funding. This funding was conditional on the country office identifying opportunities to 'grow local' by building local partnerships and leveraging additional funds from other donors for increased impact.

\section{COVID-19 Technical Interest Group}

Concurrent to ADRA's global COVID-19 strategy was the development of a global COVID-19
Technical Interest Group (TIG), established in March 2020. The TIG's membership consisted of ADRA staff with clinical, public health, WASH, social behavior change, and other relevant technical experience. The TIG regularly discussed technical matters relating to COVID-19 and provided supplementary technical materials and advice to the ADRA network.

The TIG was housed within ADRA's existing Health Technical Learning Lab, which serves to promote technical learning and dialogue on various health topics within ADRA's global office network. Because of the well-regarded reputation of the Health Technical Learning Lab, this provided a strong foundation for the TIG to develop credibility and equipped it with established communication channels through which COVID-19 technical information and materials could easily be shared.

For the first month of operation, as knowledge about COVID-19 was rapidly changing, the TIG met weekly through virtual online platforms. In April 2020 , meeting frequency was revised to every two weeks, followed by quarterly frequency in 2021 .

\section{Results}

By March 2021, ADRA had implemented 422 projects in 96 countries as a global response to the COVID-19 pandemic across ADRA's nine global regions, impacting nearly 20 million beneficiaries (see Table 2).

Table 2. Number of COVID-19 Responses and Beneficiaries by Region

\begin{tabular}{l|c|c}
\hline \multicolumn{1}{c|}{ Region } & $\begin{array}{c}\# \text { of } \\
\text { Projects }\end{array}$ & $\begin{array}{c}\# \text { of } \\
\text { Beneficiaries }\end{array}$ \\
\hline Africa & 47 & $16,015,531$ \\
\hline Asia & 75 & $1,900,000$ \\
\hline Central America/Caribbean & 10 & 54,178 \\
\hline Eastern Europe/Central Asia & 12 & 94,613 \\
\hline Europe & 32 & 42,000 \\
\hline Middle East and North Africa & 27 & 260,375 \\
\hline
\end{tabular}




\begin{tabular}{l|c|c}
\hline North America & 69 & 713,826 \\
\hline South America & 101 & 763,659 \\
\hline South Pacific & 49 & 124,938 \\
\hline TOTAL & $\mathbf{4 2 2}$ & $\mathbf{1 9 , 9 6 9 , 1 2 0}$ \\
\hline
\end{tabular}

Compared with programming from the previous five years leading up to the pandemic, ADRA's COVID-19 global response reached a greater number of beneficiaries despite fewer number of projects and smaller budget size (Table 3 ).

Table 3: Comparison of Number of Responses, Beneficiaries, and Budget Size with Previous Years

\begin{tabular}{c|c|c|c}
\hline Program Period & \# of Projects & \# Beneficiaries & Programming Budget (USD) \\
\hline 2015 & 1306 & $18,503,456$ & \$190 million \\
\hline 2016 & 1197 & $15,700,923$ & \$186 million \\
\hline 2017 & 721 & $11,028,011$ & \$219 million \\
\hline 2018 & 1043 & $16,255,597$ & $\$ 3240$ million million \\
\hline 2019 & 1181 & $13,940,984$ & $\$ 329$ million \\
\hline $202 *$ & 1372 & $20,789,281$ & $\mathbf{\$ 2 6}$ million \\
\hline
\end{tabular}

*Based on unofficial preliminary data only; 2020 figures are currently under analysis and have not yet been published through an annual report. $\dagger$ Global COVID-19 Response figures include all COVID-19 programming data in 2020 through March 2021.

A range of humanitarian needs were met as a result of ADRA's response to the pandemic. The largest need ADRA addressed was food insecurity with 129 projects (33\% of total); followed by health (103 projects, 24\%); water and sanitation (89 projects, 21\%); psychosocial support (58 projects, 14\%); health/hygiene awareness and promotion (20 projects, $5 \%$ ); and livelihoods (4 projects, $1 \%)$; with nine other projects $(2 \%)$ falling under other various categories.

Nearly $70 \%$ of projects in ADRA's global COVID-19 response were in partnership with SDA Church institutions. As a result, every \$1 USD invested by ADRA was leveraged through these partnerships with \$7 USD in outside funding. Other faith institutions such as Latter-Day Saint Charities also collaborated to increase coverage and impact. The overall budget for ADRA's global COVID-19 response equaled just under $\$ 26$ million USD.

To supplement ADRA's global response, ADRA's COVID-19 Technical Interest Group provided various technical resources to country offices to complement project implementation and ensure safety and technical accuracy. Resources included health advisories, reference documents, and ADRA-tailored webinars (see Table 4).

Table 4: ADRA COVID-19 Technical Interest Group Resources.

\begin{tabular}{l|l|l}
\hline Resource Type & Resource Title & Date of Publication \\
\hline Webinar & Planning a Promotion-Based Response to COVID-19 & 16 March 2020 \\
\hline Health Advisory & Novel Coronavirus (COVID-19) Health Advisory & 24 March 2020 \\
\hline Reference Document & Non-Personal Communication Channels for Responding to COVID-19 & 24 March 2020 \\
\hline Webinar & COVID-19: Respiratory Protection & 13 April 2020 \\
\hline Reference Document & Role of Religious Institutions and Faith Leaders in the COVID-19 Response & 14 April 2020 \\
\hline
\end{tabular}




\begin{tabular}{l|l|l}
\hline Webinar & Mental Health \& Psychosocial Support During COVID-19 & 4 May 2020 \\
\hline Repository & Workplace Key Message Materials & 22 May 2020 \\
\hline Online Forum & Conversations on Principles of Closing and Opening ADRA Offices & 25 June 2020 \\
\hline Reference Document & Involving Faith Communities in COVID-19 Response and Recovery: An Overview & 22 July 2020 \\
\hline Online Survey & COVID-19 Survey: Vaccine Questions/Concerns & 21 September 2020 \\
\hline Webinar & $\begin{array}{l}\text { COVID-19, One Health, and ADRA: Preventing Future Pandemics at the Human-Animal- } \\
\text { Environment Interface }\end{array}$ & 27 October 2020 \\
\hline Webinar & COVID-19 and Gender in WASH and Cash Transfers & 17 November 2020 \\
\hline Webinar & $\begin{array}{l}\text { Vaccine Campaigns: Lessons Learned from ADRA Polio Vaccination Campaigns and } \\
\text { Their Application for COVID-19 Vaccine Rollout }\end{array}$ & 17 February 2021 \\
\hline
\end{tabular}

\section{Discussion}

While global job loss was rampant and many organizations and institutions struggled to stay afloat during the first year of the COVID-19 pandemic, ${ }^{20}$ ADRA not only survived without losing staff or downsizing operations, but thrived. During previous years leading up to the pandemic, between 20152019, ADRA reached an average of 15.1 million beneficiaries through a range of 721-1306 projects each year. ${ }^{22-26}$ Yet with COVID-19 projects, ADRA unexpectedly reached nearly 20 million beneficiaries through 422 projects in response just to the pandemic alone, not counting other operations (which seemed largely unaffected by the additional programming ${ }^{27}$ ). By implementing a global strategy that covered ADRA's entire network of offices instead of executing separate individual responses through a fragmented approach, ADRA met and surpassed its record of beneficiaries reached in a given year, providing humanitarian relief to a greater number of vulnerable people than thought possible with the initial seed funding of merely $\$ 2.5$ million.

ADRA's faith base opened the door for much of its success. Given its relationship with the SDA Church, which carries a footprint in over 200 countries and boasts over 102,000 affiliated institutions worldwide, ${ }^{28,29}$ ADRA's potential for greater impact than the agency alone could accomplish was vast. A core element throughout the entire strategy was the focus of leveraging relationships with the SDA Church and other faith communities to capitalize on local trust, volunteer resources, public relations, and existing outreach efforts. While ADRA is affiliated with the SDA Church, partnering to conduct humanitarian interventions is not typical in many settings. Yet as a result of ADRA's intentionality to grow locally and minimize this gap within the "Stronger Together" strategy, nearly $70 \%$ of ADRA's global COVID-19 response projects were conducted in partnership with the SDA Church. The breadth of this global response, with such a relatively small overall budget, would not have been achievable without these partnerships. This indicates that capitalizing on a faith-based NGO's own faith constituents and emphasizing partnerships with affiliated institutions can have considerable effect on implementation. ADRA's 'Stronger Together' approach also provided a common framework for the SDA Church to be relevant in the communities they serve during these unprecedented times.

The expansive global footprint established with the SDA Church was instrumental in reaching the "last mile." ADRA was able to help identify the most vulnerable people in remote and hard-hit areas and deliver support quickly to those that needed it most. ADRA's partnerships with local SDA churches, their members, and their resources for implementation intensified ADRA's potential for humanitarian reach and scale. 
ADRA's global COVID-19 response was not without challenges. With so many country offices involved, capturing metrics proved difficult. Various software and dashboards used to track and record project data were not automatically translated into one centralized system. Another difficulty was determining what recovery and resilience look like, given the wide set of contexts through which ADRA was working. While ADRA is well-versed in emergency response, COVID-19 has presented complicated layers in which recovery and resilience cannot be measured in a straightforward way. Additionally, due to the scale of the pandemic's reach, it was not possible to fund programs through each of ADRA's country offices within its global network. With additional seed funds, even more ADRA offices could have been included to provide humanitarian assistance to those most in need within the respective countries.

In addition to acknowledging these difficulties, it is also important to consider this case study's limitations. Firstly, this study did not directly compare outcomes or outputs to secular NGOs, government programs, or other counterpart intuitions. Further studies could be designed to make such comparisons of programming outcomes with secular organizations to further understand the faithbased advantage. Secondly, this study does not include official data for ADRA's additional operations unrelated to COVID-19 programming in 2020, due to the delayed release of ADRA's full 2020 annual statistics. Future studies could be designed to include full and finalized data on all of ADRA's operations (beyond COVID-19 alone) for the given year under study to better understand how typical programming expenditures and beneficiary reach were impacted due to COVID-19 programming.

Nevertheless, the successes ADRA experienced with its overall response to the COVID19 pandemic provide lessons for faith-based NGOs to address future pandemics and other large-scale emergencies. By creating simple and flexible strategies that encourage local growth and partnerships, encouraging the sharing of lessons learned and other technical information among offices, and by capitalizing on collaborations with affiliated faith institutions and constituents that are already part of local communities, faith-based NGOs have a potential advantage over their secular counterparts in serving multitudes of vulnerable people.

\section{Conclusion}

Faith-based NGOs can play an essential role in response to humanitarian impacts that result from large-scale health emergencies. ADRA's experience during COVID-19 showcases how keeping a local presence in-country and fostering partnerships with affiliated faith institutions and constituents can result in a wide reach of programming, even with few funds. By providing dedicated personnel and small seed-funding, developing a flexible global strategy involving strong business continuity plans and emphasis on its faith base, and supporting the sharing of information and lessons learned among local offices, faith-based NGOs are capable of quickly delivering life-saving interventions to vulnerable communities that may otherwise not be reached. ADRA and the SDA Church have proved during the first year of COVID-19 that they are stronger together. The challenge will be to continue to leverage the global footprint to build back better, to be more resilient to future shocks, and to apply the valuable learnings that have permanently shifted humanitarian response.

\section{References}

1. Sokat YK, Altay N. Serving vulnerable populations under the threat of epidemics and pandemics. Journal of Humanitarian Logistics and Supply Chain Management. 2021. https://doi.org/10.1108/JHLSCM08-2020-0070

2. Rohwerder B. Secondary impacts of major disease outbreaks in low- and middle-income countries. K4D Helpdesk Report 756. Institute of Development Studies; 2020. Available from: https:/opendocs.ids.ac.uk/opendocs/bitstream/handle/ 
20.500.12413/15129/756_Secondary_impacts_of_maj or disease outbreak \%20in low income countries.p df? sequence $=81$ \&isAllowed $=\mathrm{y}$

3. Kelly L. Evidence and lessons on efforts to mitigate the secondary impact of past disease outbreaks and associated response and control measures [Internet]. K4D Helpdesk Report 757. Institute of Development Studies; 2020. Available from:

https://assets.publishing.service.gov.uk/media/5e6239 91e90e077e32dd80c4/757_mitigating_secondary_effe cts_of disease_outbreaks.pdf

4. Bakrania S, Chavez C, Ipince A, Rocca M, Oliver S, Stansfield C, Subrahmanian R. Impacts of pandemics and epidemics on child protection: Lessons learned from a rapid review in the context of COVID-19 [Internet]. UNICEF Office of Research - Innocenti; 2020. Available from: https:/euagenda.eu/upload/publications/wp-2020-05working-paper-impacts-pandemics-childprotection.pdf.pdf

5. Wenham C, Smith J, Davies SE, Feng H, Grépin KA, Harman S, Herten-Crabb A, Morgan R. Women are most affected by pandemics - lessons from past outbreaks. Nature. 2020;583(7815):194-8. https://doi.org/10.1038/d41586-020-02006-Z

6. Norouzi N, Zarazua de Rubens G, Choupanpiesheh S, Enevoldsen P. When pandemics impact economies and climate change: Exploring the impacts of COVID-19 on oil and electricity demand in China. Energy Research \& Social Science. 2020;64:101654. https://doi.org/10.1016/j.erss.2020.101654

7. Jena PK. Impact of pandemic COVID-19 on education in India. International Journal of Current Research. 2020;12(7):12582-6. https://doi.org/10.24941/ijcr.39209.07.2020

8. Hallgarten J. Evidence on efforts to mitigate the negative educational impact of past disease outbreaks [Internet]. K4D Helpdesk Report 793. Education Development Trust; 2020. Available from: https://opendocs.ids.ac.uk/opendocs/bitstream/handle/ 20.500.12413/15202/793 mitigating_education_effect s_of_disease_outbreaks.pdf? sequence $=6 \&$ isAllowed $=$ y

9. Mobula LM, Samaha H, Yao M, Gueye AS, Diallo B, Umutoni C, Anoko J, Lokonga JP, Minikulu L, Mossoko M, Bruni E, Carter S, Jombart T, Fall IS, Ahuka-Mundeke S. Recommendations for the COVID-19 response at the national level based on lessons learned from the Ebola virus disease outbreak in the Democratic Republic of the Congo. The American Journal of Tropical Medicine and Hygiene. 2020;103(1):12-17. https://doi.org/10.4269/ajtmh.20$\underline{0256}$

10. Rafaeli T, Hutchinson G. The secondary impacts of COVID-19 on women and girls in Sub-Saharan Africa [Internet]. K4D Helpdesk Report 830. Institute of Development Studies; 2020. Available from: https://opendocs.ids.ac.uk/opendocs/bitstream/handle/ 20.500.12413/15408/830_COVID19 girls and wom en SSA.pdf?sequence $=1 \&$ isAllowed $=y$

11. Leddy AM, Weiser SD, Palar K, Seligman H. A conceptual model for understanding the rapid COVID-19-related increase in food insecurity and its impact on health and healthcare. The American Journal of Clinical Nutrition. 2020;112(5):1162-9. https://doi.org/10.1093/ajen/nqaa226

12. Wolfson JA, Leung CW. Food insecurity and COVID-19: Disparities in early effects for US adults. Nutrients. 2020;12(6):1648. https://doi.org/10.3390/nu12061648

13. Pérez-Escamilla R, Cunningham K, Moran VH. COVID-19 and maternal and child food and nutrition insecurity: A complex syndemic. Maternal \& Child Nutrition. 2020;16(3). https://doi.org/10.1111/mcn.13036

14. Barello S, Falcó-Pegueroles A, Rosa D, Tolotti A, Graffigna G, Bonetti L. The psychosocial impact of flu influenza pandemics on healthcare workers and lessons learnt for the COVID-19 emergency: A rapid review. International Journal of Public Health. 2020;65(7):1205-16. https://doi.org/10.1007/s00038020-01463-7

15. Goldsmith S, Eimicke WB, Pineda C. Faith-based organizations versus their secular counterparts: A primer for local officials [Internet]. Ash Institute for Democratic Governance and Innovation, Harvard University; 2006. Available from: https://www.innovations.harvard.edu/sites/default/file s/11120.pdf

16. Widmer M, Betran AP, Merialdi M, Requejo J, Karpf $\mathrm{T}$. The role of faith-based organizations in maternal and newborn health care in Africa. International Journal of Gynecology \& Obstetrics. 2011;114(3):218-22. https://doi.org/10.1016/j.ijgo.2011.03.015 
17. Sakai M. Building a partnership for social service delivery in Indonesia: State and faith-based organisations. Australian Journal of Social Issues. 2016;47(3):373-88. https://doi.org/10.1002/j.18394655.2012.tb00254.x

18. Heist D, Cnaan RA. Faith-based international development work: A review. Religions. 2016;7(3):19. https://doi.org/10.3390/rel7030019

19. Agenda for Humanity. Charter for Faith-Based Humanitarian Action [Internet]. World Humanitarian Summit; 2016. Available from https://agendaforhumanity.org/sites/default/files/CHA RTER\%20FOR\%20FAITHBASED\%20HUMANITARIAN\%20ACTION.pdf

20. Smith E, Chadwick V. COVID-19 job losses accelerate in development sector, survey results say [Internet]. DEVEX; 2020. Available from https://www.devex.com/news/covid-19-job-lossesaccelerate-in-development-sector-survey-results-say$\underline{97946}$

21. ADRA International [Internet]. Silver Spring. Our story. [updated 2020; cited 2021 Mar 25]. Available from: https://adra.org/about-adra

22. ADRA International. 2015 annual report [Internet]. ADRA International; 2016. Available from: https://adra.org/wp-content/uploads/2020/02/2015ADRA-Annual-Report.pdf

Peer Reviewed: Submitted 28 April 2021, accepted 2 June 2021, published 30 July 2021

Competing Interests: None declared.

Correspondence: Emily Hirata, ADRA International, Silver Spring, MD, USA. Emily.Hirata@ADRA.org

Cite this article as: Hirata E, Peach M, Tobing S. The faith-based advantage: A case study on the Adventist Development \& Relief Agency's response to humanitarian impacts of COVID-19 as a faith-based organization. Christ J Global Health. July 2021; 8(1):24-33. https://doi.org/10.15566/cjgh.v8i1.541

(C) Authors. This is an open-access article distributed under the terms of the Creative Commons Attribution License, which permits unrestricted use, distribution, and reproduction in any medium, provided the original author and source are properly cited. To view a copy of the license, visit http://creativecommons.org/licenses/by/4.0/

\section{www.cjgh.org}

July 2021. Christian Journal for Global Health 8(1) 